\title{
MAPEAMENTO DO RISCO DE INCÊNDIOS FLORESTAIS NO MUNICÍPIO DE NOVO MUNDO, MATO GROSSO, BRASIL
}

\author{
Luciene Ribeiro' ${ }^{1}$, Ronaldo Viana Soares ${ }^{2}$, Michele Bepller ${ }^{3}$
}

(recebido: 4 de dezembro de 2009; aceito: 28 de outubro de 2011)

\begin{abstract}
RESUMO: Neste trabalho, objetivou-se elaborar um mapa de zoneamento de risco de incêndios florestais para o município de Novo Mundo, Mato Grosso. O estudo abrangeu todo o território do município, que está localizado entre as coordenadas $09^{\circ} 09^{\prime 2} 29^{\prime} \mathrm{S}$,

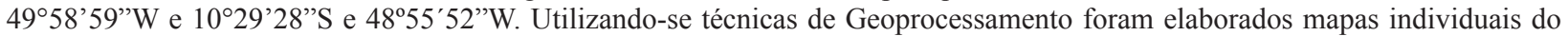
risco de incêndios florestais referentes à influência da hidrografia, da rede viária, da declividade do terreno e do uso e cobertura do solo. O risco foi classificado em seis níveis, que variaram de zero a cinco: nulo, baixo, moderado, alto, muito alto e extremo, respectivamente. Posteriormente, os mapas individuais foram sobrepostos por meio da técnica de Overlay, resultando no mapa final de zoneamento do risco de incêndio. Os resultados indicaram que $95 \%$ da área do município encontravam-se sob risco alto e muito alto. As variáveis que mais contribuíram para a obtenção desses níveis de risco foram as fronteiras entre estradas e florestas, estradas e áreas de pastagem e pastagens com florestas.
\end{abstract}

Palavras-chave: Amazônia Mato-grossense, prevenção de incêndios, fogo, proteção florestal.

\section{MAPPING OF FOREST FIRE RISK IN NOVO MUNDO COUNTY, MATO GROSSO STATE, BRAZIL}

\begin{abstract}
This research mapped forest fire risk for Novo Mundo County, located between the coordinates 0909'29”S, 4958'59”'W and $10^{\circ} 29^{\prime} 28^{\prime \prime S}$ and 48 $55^{\prime} 52^{\prime \prime}$ W, Mato Grosso State, Brazil. Using Geo-processing techniques individual risk maps for hydrograph, roads, slope and soil use and cover were elaborated. The risks were classified as null, low, high, very high, and extreme level. Afterward, the individual maps were overlaid by Overlay technical, resulting in a final fire risk zoning map. The results showed that 95\% of the studied area was under high and very high risks. The variables that most influenced the risk were the boundary areas of vegetation with roads, roads with pasture and pastures and vegetation.
\end{abstract}

Key words: Fire prevention, fire control, forest protection.

\section{INTRODUÇÃO}

O fogo é utilizado no manejo de ambientes agrícolas e pastoris por ser mais viável economicamente e já estar inserido na cultura humana há milhares de anos (MIRANDA, 2007). De acordo com Soares (1985), o fogo quando bem conduzido, por meio de planejamento adequado, gera inúmeros benefícios ao homem e ao ambiente. Mas, infelizmente, na maioria dos casos, o fogo é utilizado sem nenhum planejamento, ou com um planejamento deficiente, podendo ocorrer perda de seu controle e acarretar desastres ecológicos e perdas materiais imensuráveis.

A elaboração de planos de prevenção de incêndios florestais, presença de um batalhão de bombeiros e brigadas de combate aos incêndios florestais são de grande utilidade para campanhas de prevenção e combate ao fogo, mas a maioria dos municípios brasileiros está despreparada por ausência de programas ambientais efetivos e que, realmente, se encaixem em seu perfil (RIBEIRO et al., 2008).

O estado de Mato Grosso possui uma área territorial de $901.420,7 \mathrm{~km}^{2}$, dos quais $41 \%$ estão representados pelo ecossistema de Cerrado, 7\% pelo Pantanal e 52\% pela Floresta Amazônica (LUCIARDO et al., 2004), sendo que esta última cobre grande parte do norte do estado. A proximidade do município de Novo Mundo com a BR 163, importante rodovia que liga o norte do estado com outros estados e regiões, desperta um vislumbre de progresso em um futuro próximo, fator que estimula a exploração intensa dos recursos naturais e formação de novos municípios, oriundos do desmembramento de outros, gerando novas estradas, maior área desmatada e queimada para instalação de fazendas e assentamentos rurais (FEARNSIDE, 2006).

\footnotetext{
${ }^{1}$ Bióloga, Dra. em Engenharia Florestal - Laboratório de Incêndios Florestais - Departamento de Ciências Florestais - Universidade Federal do Paraná/UFPR - Av. Pref. Lothário Meissner, 900, J. Botânico - 80210170 - Curitiba, PR - lucienefloresta@gmail.com

${ }^{2}$ Engenheiro Florestal, Professor Dr. em Engenharia Florestal - Laboratório de Incêndios Florestais - Departamento de Ciências Florestais Universidade Federal do Paraná/UFPR - Av. Pref. Lothário Meissner, 900, J. Botânico - 80210170 - Curitiba, PR - rvsoares@ufpr.br

${ }^{3}$ Engenheira Cartógrafa, Professora MSc.em Ciências Geodésicas - Instituto Federal de Educação, Ciência e Tecnologia da Paraíba/IFPB - Rua $1^{\circ}$ de maio, 720, Jaguaribe - 58015-430 - João Pessoa, PB - michelebeppler@ifpb.edu.br
}

Cerne, Lavras, v. 18, n. 1, p. 117-126, jan./mar. 2012 
Para Lentini et al. (2003), em regiões onde há um período definido de seca, a atenção deve ser especial, com elaboração direcionada e adequada de políticas que venham minimizar a ação do fogo, já que os riscos são mais altos neste período. Nesse sentido, os mapas de risco de incêndios florestais se constituem em ferramentas eficazes para o conhecimento das áreas mais suscetíveis, possibilitando a geração de investimentos em medidas preventivas quanto aos riscos de incêndios florestais e em pontos específicos de maior risco (BATISTA, 2000; FERRAZ; VETTORAZZI, 1998).

Conduziu-se este trabalho, com o objetivo de elaborar um mapa de zoneamento de risco de incêndios para o município de Novo Mundo, Mato Grosso, contribuindo, assim, para que a tomada de decisão quanto aos investimentos na prevenção e controle dos incêndios florestais deste município sejam mais eficientes.

\section{MATERIAL E MÉTODOS}

O município de Novo Mundo está localizado no estado de Mato Grosso, entre as coordenadas $09^{\circ} 09^{\prime} 29^{\prime \prime} \mathrm{S}$, $49^{\circ} 58^{\prime} 59^{\prime \prime} \mathrm{W}$ e $10^{\circ} 29^{\prime} 28^{\prime \prime} \mathrm{S}$ e $48^{\circ} 55^{\prime} 52^{\prime \prime} \mathrm{W}$ e abrange uma área de $5.794,7 \mathrm{~km}^{2}$. A altitude média da sede do município é de $330 \mathrm{~m}$. O clima da região, segundo a classificação de Köppen é do tipo Aw, caracterizando-se como equatorial quente e úmido, com dois a cinco meses de seca. Os valores médios anuais de precipitação e temperatura foram de 2000 $\mathrm{mm} \mathrm{e} 25^{\circ} \mathrm{C}$, respectivamente, durante o período de estudos.

O mapa de uso e cobertura do solo foi obtido por classificação de imagem orbital. O software utilizado para a classificação foi o E-Cognition 4.0 (BAATZ; SCHÄPE, 2006) com utilização do método de Classificação Orientada a Objeto, aplicando-se a técnica Bottom-up (de baixo para cima) e Top-down (de cima para baixo) para a segmentação. As informações temáticas obtidas pela classificação no software E-Cognition 4.0 foram exportadas e manipuladas no software Arc-View 9.0. As imagens CBERS, cenas 166 e 167, obtidas junto ao INPE já se encontravam referenciadas pelo Sistema Geodésico de Referência WGS84 e datam de 07 e 10/08/2006. Foram utilizadas as bandas espectrais 2, 3 e 4, referentes aos comprimentos de onda do verde $(0,52-0,59 \mu \mathrm{m})$, vermelho $(0,63-0,69 \mu \mathrm{m})$ e infravermelho próximo $(0,77-0,89 \mu \mathrm{m})$, respectivamente. Como se observa na Figura 1, o uso e a cobertura do solo em 2006 ocorriam da seguinte maneira: a Floresta Ombrófila Aberta ou de Transição (FOA) ocupava $2208,86 \mathrm{~km}^{2}(38,1 \%)$, a Savana $1229,54 \mathrm{~km}^{2}(21,2 \%)$, a Pastagem 2173,59 km² (37,5\%), os Corpos de Água 47,36 $\mathrm{km}^{2}(0,8 \%)$, o Afloramento Rochoso $115,94 \mathrm{~km}^{2}(2,0) \% \mathrm{e}$ a Agricultura 19,42 km² (0,3\%), perfazendo $5794,7 \mathrm{~km}^{2}$.
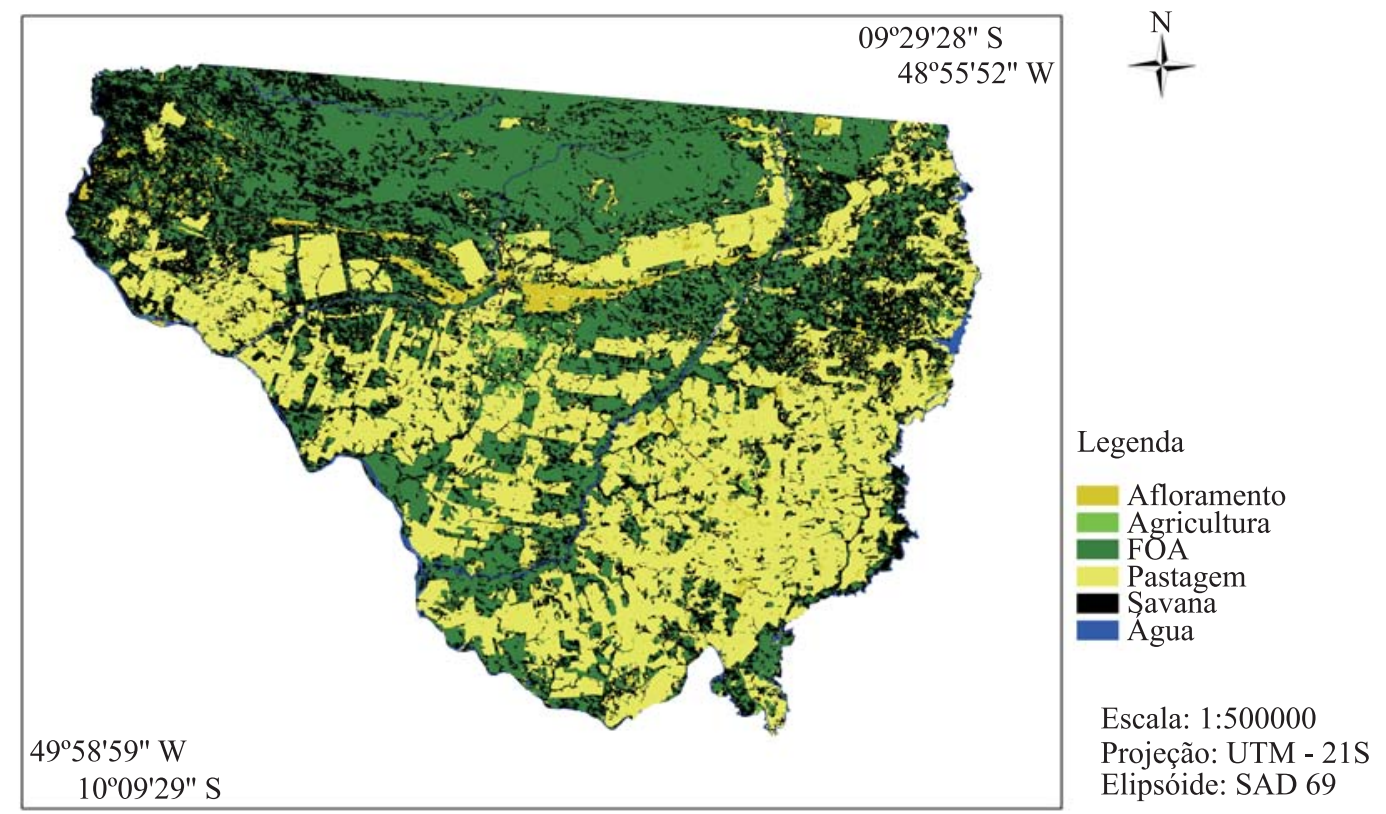

Figura 1 - Uso e cobertura do solo no município de Novo Mundo, MT, em 2006.

Figure 1 - Soil occupation and cover in Novo Mundo County in 2006.

Cerne, Lavras, v. 18, n. 1, p. 117-126, jan./mar. 2012 
De posse dos dados obtidos da classificação da imagem e da base cartográfica do município, foram elaborados mapas de risco preliminares referentes à declividade do terreno, rede hidrográfica e viária e uso e cobertura do solo, seguindo a metodologia proposta por Batista et al. (2002), Chuvieco e Congalton (1989) e Salas e Chuvieco (1994). De acordo com o nível de risco, os pesos foram atribuídos conforme consta na Tabela 1 .

Tabela 1 - Peso adotado de acordo com o grau de risco de incêndio no município de Novo Mundo, MT.

Table 1 - Selected weights according to the risk fire degree in Novo Mundo County, Mato Grosso State.

\begin{tabular}{lc}
\hline Grau de risco & Peso adotado \\
\hline Nulo & 0 \\
Baixo & 1 \\
Moderado & 2 \\
Alto & 3 \\
Muito alto & 4 \\
Extremo & 5 \\
\hline
\end{tabular}

Fonte: Batista et al. (2002), Chuvieco e Congalton (1989) e Salas e Chuvieco (1994).

Declividade do terreno: O Modelo de Elevação Digital do Terreno foi obtido a partir dos arquivos oriundos dos dados do Shuttle Radar Topography Mission - SRTM (2006). A Tabela 2 relaciona a inclinação do terreno em função da sua influência na taxa de propagação do fogo (SOARES, 1984).

Tabela 2 - Classes de declividade do terreno e pesos adotados no município de Novo Mundo, MT.

Table 2 - Selected weights according to the slope degree in Novo Mundo County, Mato Grosso State.

\begin{tabular}{lccccc}
\hline $\begin{array}{l}\text { Classes de } \\
\text { declividade (\%) }\end{array}$ & $0-15$ & $16-25$ & $26-35$ & $36-45$ & $46-55$ \\
\hline $\begin{array}{l}\text { Fator de propagação } \\
\text { Peso adotado }\end{array}$ & 1,00 & 1,05 & 1,15 & 1,20 & 1,25 \\
\hline
\end{tabular}

Fonte: Soares (1984).

Rede hidrográfica: O raio de influência foi de 50 metros para os rios, sendo considerados apenas aqueles que apresentavam largura compatível com a resolução espacial da imagem utilizada, como os rios Teles Pires, Peixoto de Azevedo, Cristalino, Rochedo e Anhadu. Esse raio de influência foi definido pela presença de vários trechos de vegetação ao longo das margens dos rios que podem se tornar susceptiveis à entrada do fogo pela influência fluvial.

Rede viária: As áreas delimitadas pelos raios de influência foram consideradas sob risco pelo potencial de ignição de incêndios próximos à estrada. Nesse caso, o raio de influência para a rede viária foi de 50 metros, pois de acordo com Chou et al. (1990) o raio de risco em autoestradas é, em média, de 100 metros e varia de acordo com as caracteristicas de cada região. No município em questão, as autoestradas não são pavimentadas, fazem fronteiras com florestas e pastagens e servem de ligação entre o núcleo urbano e a zona rural, cujo tráfego é principalmente de agricultores locais. Existem vários carreadores feitos pelos próprios moradores que logo se tornam estradas extraoficiais, fato que contribui para o aumento dos riscos de incêndios florestais.

O raio de influência da rede hidrográfica e viária possui o mesmo tipo de classificação (sob influência e sem influência), mesmo tipo de risco (sim e não) e mesmo peso (1 e 0 ). Tal fato permitiu que ambas fossem colocadas na mesma tabela (Tabela 3).

Tabela 3 - Classificação segundo a influência da hidrografia e rede viária no município de Novo Mundo, MT.

Table 3 - Selected weights to describe hydrographic and road network influences in Novo Mundo County, Mato Grosso State.

\begin{tabular}{lcc}
\hline Classes & Riscos & Peso adotado \\
\hline Sob influência & Sim & 1 \\
Sem influência & Não & 0 \\
\hline
\end{tabular}

Fonte: Salas e Chuvieco (1994).

Uso e cobertura do solo: Os pesos atribuídos ao uso e cobertura do solo foram resultantes do potencial de riscos de cada tipo de uso, a saber:

- a presença de corpos d'água em uma dada região é um elemento que pode causar dupla influência quanto aos riscos de fogo. Podem ser considerados como barreiras ao fogo ou pontos de apoio para apagar um incêndio. No entanto, podem também ser fontes de fogo, causado por atividades de recreação, rituais religiosos e pesca, quando uma fogueira mal apagada pode iniciar um incêndio florestal;

- os Afloramentos rochosos, presentes na área de estudo, não apresentavam vegetação ou apresentavam vegetação rala, de forma que o risco de fogo foi considerado nulo;

Cerne, Lavras, v. 18, n. 1, p. 117-126, jan./mar. 2012 
- o município possui em seu território a maior parte do Parque Estadual Cristalino I e II, que constitui importante área para a conservação da Amazônia brasileira, decorrente da sua biodiversidade ainda pouco conhecida (CAMPELLO et al., 2002), tratando-se de uma região prioritária para a conservação junto ao Ministério do Meio Ambiente (MMA). Estão presentes no município 23 assentamentos rurais, onde a agricultura é principalmente de subsistência e conduzida de forma empírica, sendo o fogo a principal forma de manejo, com ausência de mecanismos para seu controle. Em observações de campo verificou-se que os plantios chegavam até as bordas da floresta (Área de Reserva Legal) que no município é comum a todos os lotes de um assentamento. Dessa forma, para a agricultura foi considerado o risco alto;

- a Floresta Ombrófila Aberta ou de Transição (FOA) corre riscos iminentes de incêndios por formação de clareiras oriundas da retirada de madeira, construção de estradas em seu interior e proximidade com a vizinhança (fazendas e assentamentos, cuja principal atividade é a pastagem, consequentemente, uso do fogo);

- a Savana, por suas características intrínsecas de vegetação possui risco muito alto, somando-se a isso a presença de grandes fazendas e assentamentos (cuja principal atividade é a pastagem), além das estradas que cortam esta porção do território municipal;

- a pastagem apresenta risco extremo, em razão do uso do fogo para formação e renovação, além de margear as estradas e florestas em grande parte do município.

Dessa forma, os pesos atribuídos ao uso e cobertura do solo tiveram como base a Tabela 4.

Zoneamento de riscos: O mapa de zoneamento de risco de incêndio florestal foi elaborado a partir da técnica da superposição (overlay) dos mapas temáticos e em função da somatória ponderada dos riscos parciais de cada variável previamente analisada como proposta por Batista et al. (2002), Chuvieco e Congalton (1989) e Salas e Chuvieco (1994). O modelo de integração dos dados foi expressa pela seguinte equação:

$$
\mathrm{RISCO}=\mathrm{DV}+\mathrm{HD}+\mathrm{RV}+\mathrm{CS}, \text { onde: }
$$

$\mathrm{DV}=$ coeficiente de risco segundo a declividade

$\mathrm{HD}=$ coeficiente de risco segundo a hidrografia

$\mathrm{RV}=$ coeficiente de risco segundo a rede viária

$\mathrm{CS}=$ coeficiente de risco segundo a cobertura do solo

Tendo em vista que para cada classe foi atribuído um grau de risco, observou-se que, ao final da somatória do risco de todas as classes, o valor máximo não ultrapassaria 8 e o mínimo não seria inferior a 1 . Como as classes representadas foram apenas 5 , efetuou-se uma classificação por intervalos constantes, resultando nos intervalos ilustrados na Tabela 5.

\section{RESULTADOS E DISCUSSÃO}

\subsection{Mapas temáticos de riscos de incêndios florestais}

Declividade: A topografia tem influência direta sobre o clima e sobre o tipo de vegetação que se estabelece em uma determinada área. Esse tipo de influência ocorre, em razão das condições de vento, umidade do ar e do material combustível, em associação com o nível topográfico do terreno. Dessa forma, a declividade influencia também no comportamento do fogo, sendo que em aclives o fogo se propaga muito mais rapidamente do que em declives, principalmente quando os aclives são bem acentuados.

Tabela 4 - Pesos adotados de acordo com o uso e cobertura do solo no município de Novo Mundo, MT.

Table 4 - Selected weights according to the soil occupation in Novo Mundo County, Mato Grosso State.

\begin{tabular}{lcccccc}
\hline Tipo de uso & Água & Afloramento rochoso & Agricultura & FOA & Savana & Pastagem \\
\hline Grau de risco & Nulo & Nulo & Alto & Alto & Muito alto & Extremo \\
Peso adotado & 0 & 0 & 3 & 3 & 4 & 5 \\
\hline
\end{tabular}

Fonte: Chuvieco e Congalton (1989) e Salas e Chuvieco (1994), adaptado pelo autor.

Tabela 5 - Graus e classes de riscos de incêndios florestais no município de Novo Mundo, MT.

Table 5 - Forest fire risk rank in Novo Mundo County, Mato Grosso State.

\begin{tabular}{lccccccc}
\hline Grau de risco & Nulo & Baixo & Moderado & Alto & Muito Alto & Extremo \\
\hline Classes de riscos & 0 & $1-2$ & 3 & $4-5$ & 6 & $7-8$ \\
\hline
\end{tabular}

Fonte: Batista et al. (2002), Chuvieco e Congalton (1989) e Salas e Chuvieco (1994). Adaptado pelo autor.

Cerne, Lavras, v. 18, n. 1, p. 117-126, jan./mar. 2012 
Soares (1984) narra medições realizadas em incêndios de Eucalyptus na Austrália que mostraram que o fogo pode dobrar de velocidade em aclives de $10^{\circ}$ e quadruplicar em aclives de $20^{\circ}$. Este autor cita também que estudos de laboratório desenvolvidos pela queima de "camas" de acículas colocadas a diversos graus de inclinação mostraram a mesma tendência, embora com aumentos na taxa de propagação bem menores que os observados no campo. O mapa de risco relativo à declividade (Figura 2) demonstrou um risco baixo para todo o município, pois o percentual não ultrapassou $15 \%$ e valores inferiores a este não representam riscos maiores.

Hidrografia: A importância da rede hidrográfica para os riscos de incêndios florestais varia de região para região ou, até mesmo, em uma mesma região, dependendo da dimensão dela, bem como do uso que se faz desses recursos. Seguramente, nem todas as margens de rios podem significar algum tipo de risco de incêndios florestal. No entanto, para definir os riscos exatos de cada trecho de margem de um município é necessário tempo e exclusividade no estudo, o que não foi possível no presente trabalho.

Um inventário botânico de espécies vasculares foi realizado por Zappi et al. (2011), na região de Novo Mundo, onde foram descritas as caracteristicas da vegetação que ocorrem nas margens dos rios Cristalino e Teles Pires como vegetação fechada, vegetação aberta, abundância de cipós e presença de populações monoespecíficas de algumas espécies arbóreas. Segundo este estudo, a vegetação é submetida a forte insolação e direta influência fluvial.

A vegetação presente em vários trechos de margem e com as características verificadas por Zappi et al. (2011), aliada à presença de rios de primeira, segunda e terceira ordem, além de várias nascentes e represas, aumenta sensivelmente a problemática do fogo no período mais seco, quando a vegetação está mais susceptível e o calor intenso estimula as atividades recreativas.

Vários lotes e grandes fazendas são banhados pelos rios que possuem grande importância no contexto do fogo, pois poderiam funcionar como pontos de coletas de água para controlar um incêndio e também servirem de aceiro contra o fogo que se origina no vizinho. Por outro lado, também sofrem influência direta do fogo para limpeza, pois muitos proprietários "limpam" as margens para ter melhor acesso à água para o consumo humano e animal. Em Novo Mundo, a grande extensão da rede hidrográfica, utilizada para recreação e pesca, inclui também um meio de transporte, onde, por meio de barcas, atravessa-se de um município ao outro. Dessa forma, o raio de influência definido no presente trabalho possibilitou uma área de risco de $61,61 \mathrm{~km}^{2}$ ou $1,06 \%$ (Figura 3).
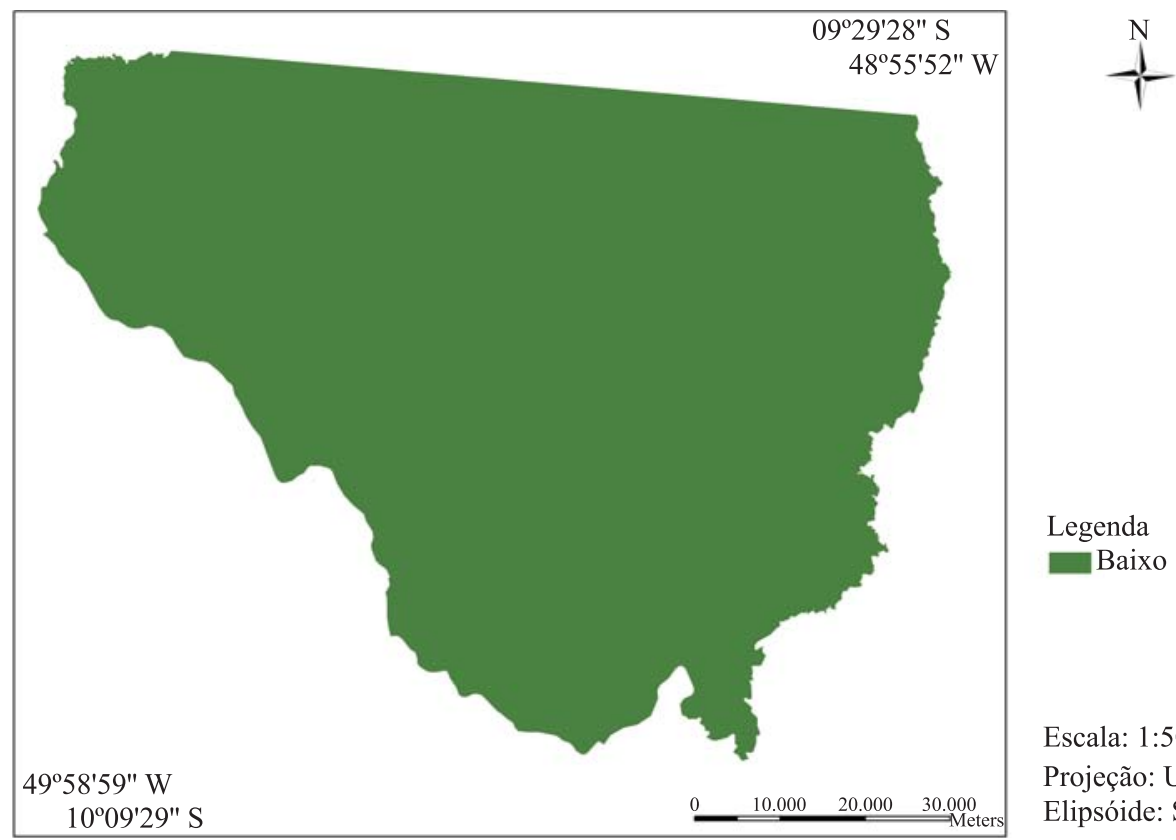

Escala: 1:500000

Projeção: UTM - 21S

Elipsóide: SAD 69

Figura 2 - Risco de incêndios florestais quanto à declividade do terreno no município de Novo Mundo, MT.

Figure 2 - Forest fires risk due to the slope in Novo Mundo County, Mato Grosso State.

Cerne, Lavras, v. 18, n. 1, p. 117-126, jan./mar. 2012 

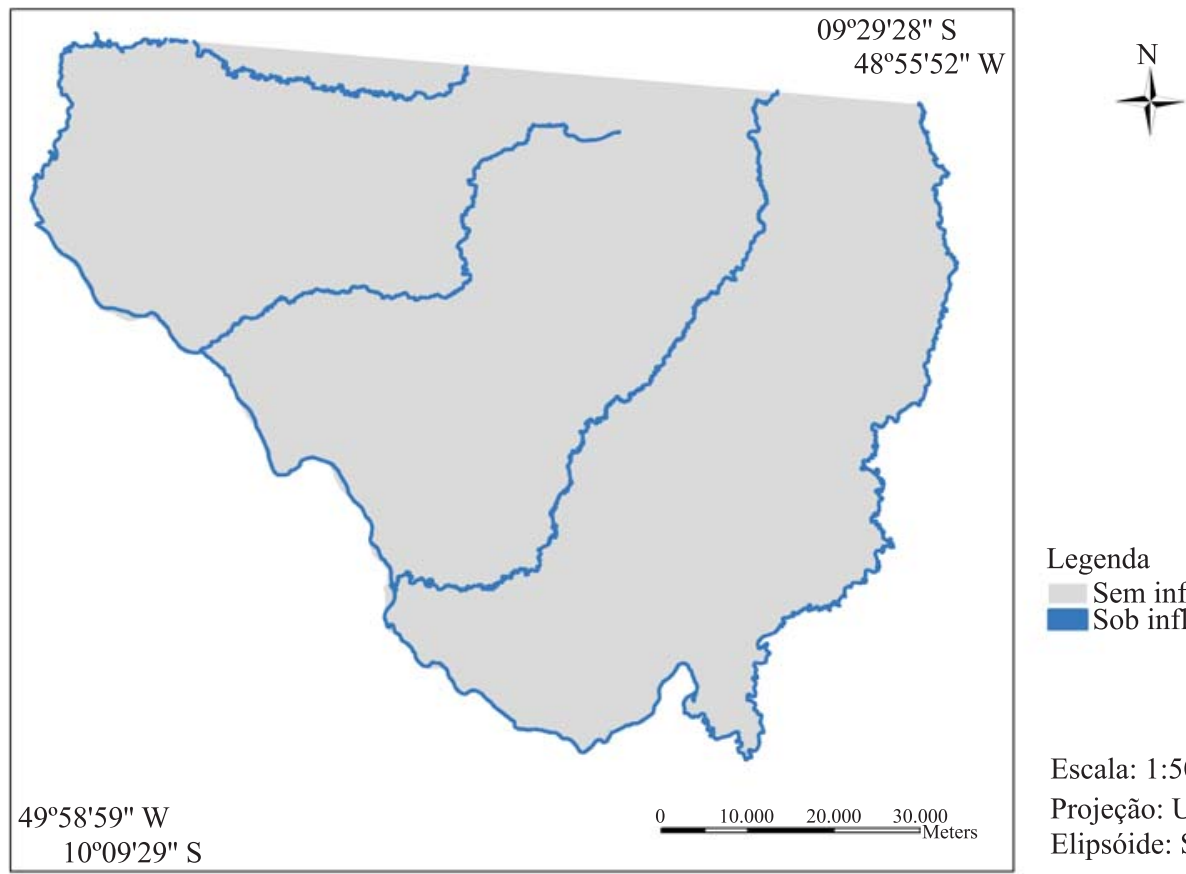

Legenda

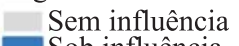

Sob influência

Escala: 1:500000

Projeção: UTM - 21S

Elipsóide: SAD 69

Figura 3 - Influência da hidrografia quanto ao risco de incêndios florestais no município de Novo Mundo, MT.

Figure 3 - Fire risk due to the hydrograph in Novo Mundo County, Mato Grosso State.

Rede viária: As estradas constituem riscos de incêndios florestais, à medida que contribuem na abertura de novas áreas de exploração agropastoril e retirada de madeira de áreas antes inacessíveis, formando clareiras que contribuem para mudanças do microclima local, facilitando a entrada do fogo. Ainda, a abertura de novas estradas dentro do município se torna responsável pelo acúmulo de material combustível às suas margens. Nos meses mais críticos do período seco, as estradas se tornam perigosas, pois um agente de ignição, como por exemplo, um fumante, pode causar incêndios de grandes dimensões por não serem prontamente detectados. O risco proporcionado pela rede viária está relacionado também à forma de uso e cobertura do solo, uma vez que, na área de estudo, a pastagem chegava até às margens das estradas e não existia nenhum tipo de barreira contra o fogo. Segundo relatos dos moradores, descrito por Ribeiro et al. (2008), grande parte dos incêndios ocorridos no município em anos passados teve inicio às margens das estradas. Estudos conduzidos por Brandão Júnior et al. (2007) indicaram que as estradas não oficiais apresentam importante contribuição no desmatamento e, consequentemente, para queimadas de vastas áreas na Amazônia. Esses autores comentaram que a maior parte das estradas não oficiais é construída por iniciativa privada e sequer constam nos mapas oficiais do IBGE (Instituto Brasileiro de Geografia e Estatística) e do Departamento Nacional de Infraestrutura e Transporte (DENIT). O risco de incêndio florestal influenciado pela presença das estradas está representado na Figura 4, significando que $119,57 \mathrm{~km}^{2}$ ou 2,06 \% estavam sob influência delas, no que tange aos riscos de incêndios florestais. Esses valores equivalem às estradas oficiais, não se contabilizando as estradas não oficiais e os carreadores. Nesse sentido, acredita-se que o valor de influência proporcionado pelas margens das estradas pode ser bem maior que o obtido no presente trabalho.

Uso e cobertura do solo: As atividades produtivas que estão ao redor da floresta influenciam diretamente na suscetibilidade ao fogo, que se dará de acordo com o nível de alteração do ambiente e com as características físicas e químicas da vegetação. Os riscos de incêndios florestais quanto ao uso e cobertura do solo estão representados na Figura 5.

Risco nulo: representou $103,30 \mathrm{~km}^{2}(2,8 \%)$ da área do município, constituindo-se na soma das regiões onde não há o risco de incêndios florestais, como dentro dos corpos de água e em afloramentos rochosos, sendo que neste último, de acordo com Zappi et al. (2011) existe

Cerne, Lavras, v. 18, n. 1, p. 117-126, jan./mar. 2012 

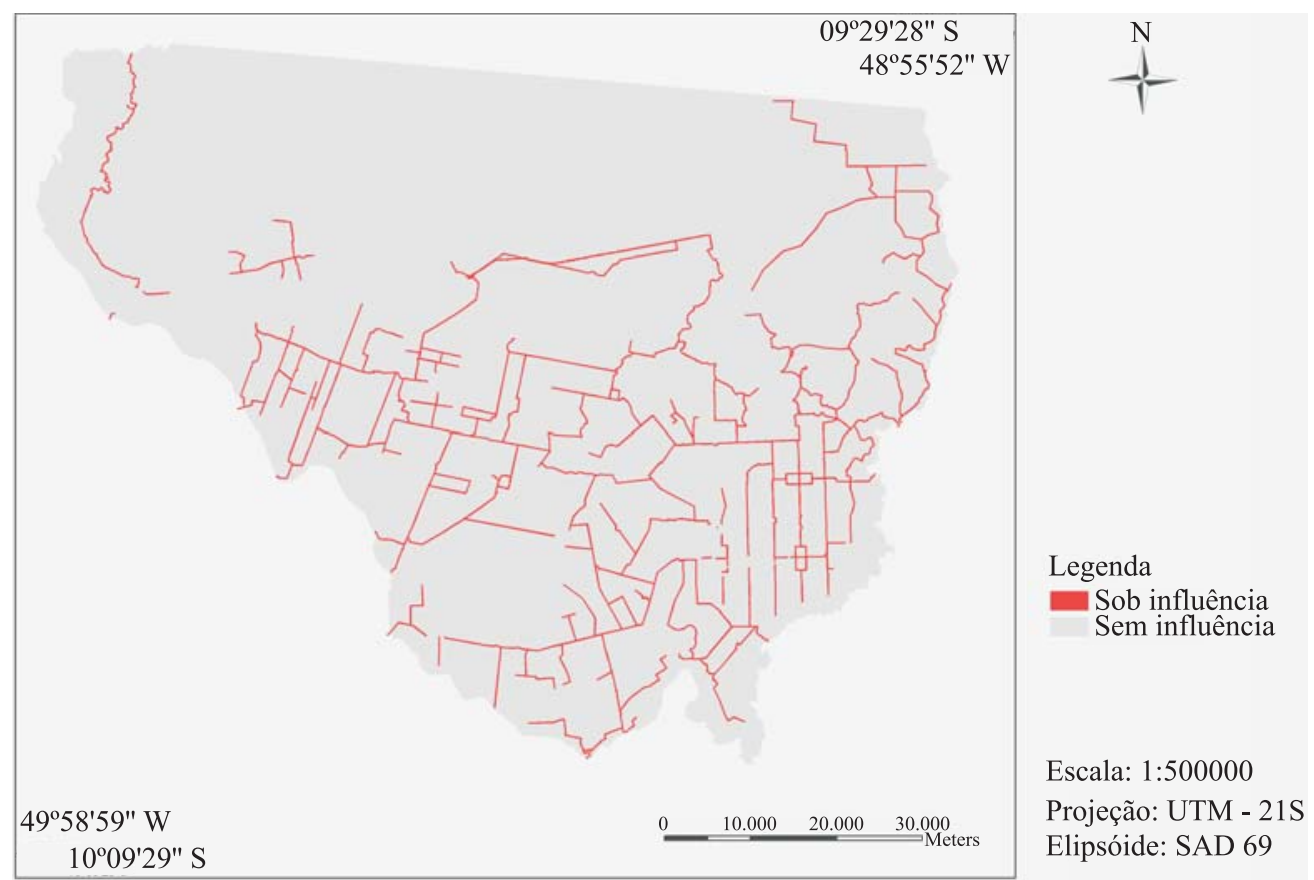

Figura 4 - Influência da rede viária quanto ao risco de incêndios florestais no município de Novo Mundo, MT.

Figure 4 - Fire risk to the roads network in Novo Mundo County, Mato Grosso State.
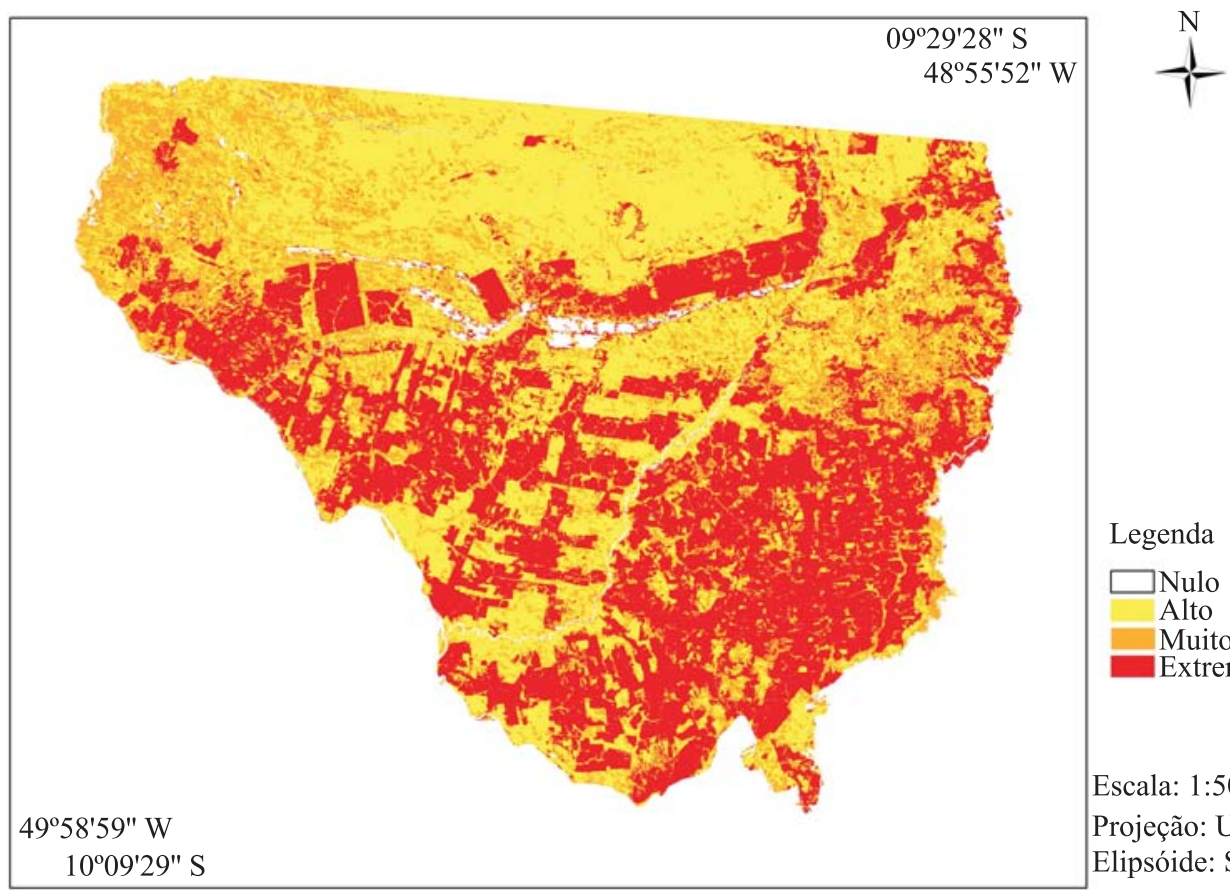

Legenda

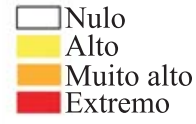

Escala: 1:500000

Projeção: UTM - 21S

Elipsóide: SAD 69

Figura 5 - Risco de incêndios florestais quanto à cobertura do solo no município de Novo Mundo, MT.

Figure 5 - Fire risk due to the use of soil in Novo Mundo County, Mato Grosso State.

Cerne, Lavras, v. 18, n. 1, p. 117-126, jan./mar. 2012 
vegetação aberta com arvoretas e arbustos esparsos, que crescem em ilhas de solo sobre as rochas ou em fendas entre elas, com herbáceas rupícolas, especialmente bromélias, samambaias e orquídeas.

Risco alto: representou $2228,27 \mathrm{~km}^{2}(38,5 \%)$, estando relacionado basicamente à tipologia florestal Floresta Ombrófila Aberta ou de Transição, localizada em sua maior parte dentro do Parque do Cristalino I e II. Com exceção do Parque, parte dessa tipologia que ainda existe, está distribuída pelo município, sendo resultante do remanescente vegetal obrigatório, tal como Área de Reserva Legal (ARL) e Áreas de Preservação Permanente (APP). Risco muito alto: representou 1229,54 km $\mathrm{km}^{2}(21,2 \%)$ e se referiu principalmente à região que contém vegetação do tipo Savana, localizadas nas regiões mais altas do município. Essas áreas estão ocupadas por assentamentos rurais e grandes fazendas, cuja principal atividade é a pastagem. A exploração vegetal ocorre em maior incidência, em razão da escassez de fiscalização por órgãos ambientais, decorrentes da precariedade das estradas, além da distância da sede do município. Risco extremo: referiu-se às pastagens e representou $2173,59 \mathrm{~km}^{2}(37,5 \%)$ da área, merecendo, portanto, um cuidado especial no que se refere a medidas profiláticas quanto aos incêndios florestais.

\subsection{Zoneamento de riscos de incêndios florestais}

O zoneamento de riscos de incêndio florestais (Figura 6) traduziu os níveis de riscos obtidos para o município de Novo Mundo. Esses riscos estão interligados entre si pela forma de manejo de todas as atividades, onde um fator incrementa o risco de outro e, assim, consecutivamente.

Risco nulo: representou 103,28 $\mathrm{km}^{2}(1,8 \%)$ e se referiu somente ao afloramento rochoso e ao interior dos corpos de água. Os riscos categorizados como baixo e moderado representaram juntos $14,60 \mathrm{~km}^{2}(0,3 \%)$ e se referiram à influência da agricultura, incipiente no município. Risco alto: representou 3454,82 $\mathrm{km}^{2}$ (59,6\%) estando relacionado à porção coberta pela Floresta Ombrófila Aberta ou de Transição e os remanescentes florestais dessa tipologia, presente predominantemente dentro do Parque Estadual do Cristalino I e II e espalhada pelo município, além de parte de Savana protegida pelo Parque. A grande extensão da rede hidrográfica também contribuiu para esse nível de risco. Risco muito alto: totalizou 2105,56 $\mathrm{km}^{2}(36,3 \%)$ e abrangeu as áreas de pastagem, bem como as áreas de Floresta Ombrófila Aberta e de Transição e Savana que fazem contato com as pastagens.
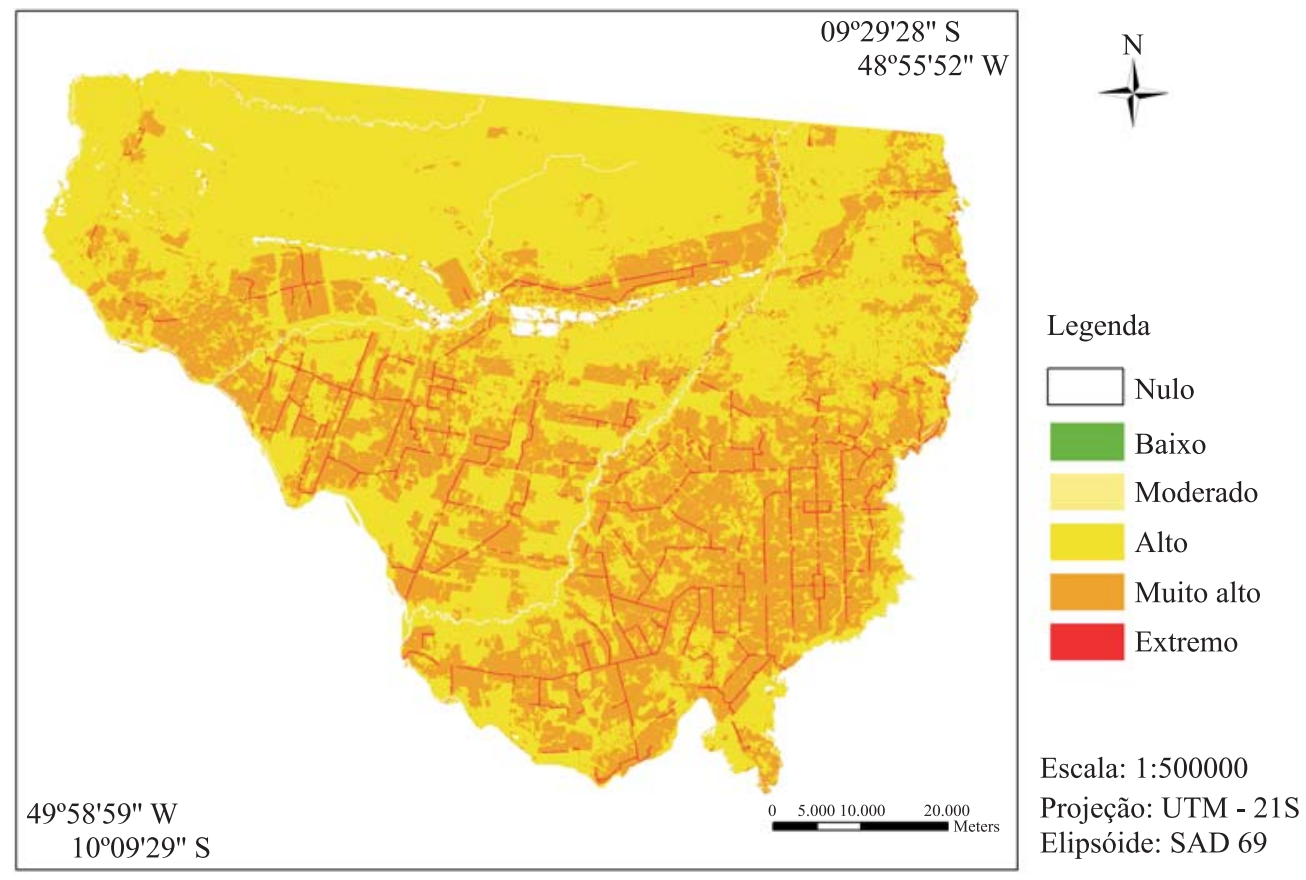

Figura 6 - Zoneamento de risco de incêndios florestais no município de Novo Mundo, MT.

Figure 6 - Forest fire risk map in Novo Mundo County, Mato Grosso State.

Cerne, Lavras, v. 18, n. 1, p. 117-126, jan./mar. 2012 
Esse nível de risco de incêndio ocorreu também ao redor do Parque Cristalino I e II, em decorrência da característica da vizinhança, composta de vários assentamentos rurais e grandes fazendas de pecuária, representando uma ameaça à integridade física dele no que tange aos riscos de incêndios florestais. Risco Extremo: representou 94,99 km² (1,6\%) e se referiu, principalmente, às margens das estradas próximas às pastagens e às florestas, pois o fogo pode ser oriundo tanto das margens das estradas para as pastagens e florestas, como das pastagens para as florestas.

\section{CONCLUSÕES}

A rede viária e o uso e cobertura do solo, em decorrência da pecuária extensiva, foram as variáveis do meio físico que mais influenciaram no risco de incêndios. Pode-se afirmar também que a integração das variáveis ambientais possibilitou uma visão ampla dos locais onde os riscos são iminentes, apontando as áreas mais suscetíveis aos riscos de incêndios como sendo as margens das estradas com as florestas e as pastagens e margens de pastagens com florestas. Tal informação, em nível municipal, gera informações mais detalhadas sobre a área de risco e possibilita a tomada de decisão em pontos estratégicos onde se faz necessária a aplicação de medidas preventivas.

No caso do município de Novo Mundo sugerese: 1) a implantação de cortinas verdes entre estradas e pastagens; 2) aceiro permanente de tamanho proporcional entre as estradas e florestas e entre pastagens e florestas; 3) definição de pontos de apoio para coleta de água, em caso de incêndios; 4) divulgação do nível de risco de fogo no período mais critico do ano, utilizando-se meios de comunicação local que melhor alcancem os habitantes, tal como rádio e panfletos; 5) colocação de placas nas estradas, salientando os cuidados, punições legais, bem como as medidas a serem tomadas em caso de incêndio florestal.

O fato de o município estudado ser jovem e ainda conter em seu território uma grande porção florestal, rede hidrográfica extensa, fauna e flora exuberante e ainda pouco estudada cientificamente, comprovado pelas poucas publicações bibliográficas disponíveis, torna esse município um local adequado para a elaboração de plano eficiente de prevenção e combate a incêndios florestais.

\section{REFERÊNCIAS}

BAATZ, M.; SCHÄPE, A. Mutiresolution segmentation: an optimization approach for high quality multiscale image segmentation. Disponível em: $<$ http://www.definiens.com>. Acesso em: 10 mar. 2006.
BATISTA, A. C. Mapas de risco: uma alternativa para o planejamento de controle de incêndios florestais. Revista Floresta, Curitiba, v. 30, n. 1/2, p. 45-54, jun./dez. 2000.

BATISTA, A. C. et al. Zoneamento de risco de incêndios florestais para o estado do Paraná. Curitiba: FUPEF, 2002. $86 \mathrm{p}$.

BRANDÃO JÚNIOR, A. O. et al. Desmatamento e estradas não-oficiais da Amazônia. In: SIMPÓSIO BRASILEIRO DE SENSORIAMENTO REMOTO, 13., 2007, Florianópolis. Anais... Florianópolis: INPE, 2007. p. 2357-2364.

CAMPELLO, S. et al. Diagnóstico do Parque Estadual

Cristalino. Brasília: Ministério do Meio Ambiente, 2002.

CHOU, Y. et al. Spatial autocorrelation of wildfire distribution in the Idyllwild Quadrangle, San Jacinto Motains, California, USA. Environmental Management, New York, v. 17, n. 1, p. 129-140, 1990.

CHUVIECO, E.; CONGALTON, R. G. Aplication of remote sensing and geographic information systems to forest fire hazard mapping. Remote Sensoring of Enviromment, New York, v. 29, p. 147-159, 1989.

FEARNSIDE, P. M. Desmatamento na Amazônia: dinâmica, impactos e controle. Acta Amazônica, Manaus, v. 36, n. 3, p. 395-400, 2006.

LENTINI, M. et al. Fatos florestais da Amazônia 2003. Belém: Instituto do Homem e Meio Ambiente da Amazônia, 2003. 110 p.

LUCIARDO, R. O. et al. Identificação e proposição de métodos de valoração econômica dos efeitos das queimadas no estado de Mato Grosso. In: CONGRESSO DA SOBER, 10., 2004, Cuiabá. Anais... Cuiabá: UFMT, 2004. p. 14.

MIRANDA, E. E. Quando o Amazonas corria para o

Pacífico. Petrópolis: Vozes, 2007. 253 p.

RIBEIRO, L. et al. Percepção e uso do fogo por produtores rurais do município de Novo Mundo, Amazônia Mato-grossense, Brasil. In: SIMPÓSIO DE PÓS-GRADUAÇÃO EM CIÊNCIAS FLORESTAIS, 5., 2008, Brasília. Anais... Brasília, 2008. p. 9.

SALAS, J.; CHUVIECO, E. Geographic information systems for wildland fire risk mapping. Wildfire, Washington, v. 3, n. 2, p. 7-13, June 1994.

Cerne, Lavras, v. 18, n. 1, p. 117-126, jan./mar. 2012 
SHUTTLE RADAR TOPOGRAPHY MISSION. Disponível em: <ftp://edesgs9.cr.usgs.gov/pub/data/srtm/South_ America/>. Acesso em: 12 jun. 2006.

SOARES, R. V. Incêndios florestais: controle e uso do fogo. Curitiba: FUPEF, 1985. 213 p.
SOARES, R. V. Prevenção e controle de incêndios florestais. Curitiba: FUPEF, 1984. 160 p.

ZAPPI, D. C. et al. Plantas vasculares da região do Parque Estadual Cristalino, norte de Mato Grosso, Brasil. Acta Amazônica, Manaus, v. 41, n. 1, p. 29-38, mar. 2011.

Cerne, Lavras, v. 18, n. 1, p. 117-126, jan./mar. 2012 